\title{
PERANCANGAN SISTEM INFORMASI PROMOSI BERBASIS WEB
}

\author{
Rometdo Muzawi'), Yoyon Efendi ${ }^{2}$ ) \\ ${ }^{1}$ Manajemen Informatika, STMIK Amik Riau, Jl. Purwodadi Km 10,5 Pekanbaru \\ ${ }^{2}$ Teknik Informatika, STMIK Amik Riau, Jl. Purwodadi Km 10,5 Pekanbaru \\ email: rometdomuzawi@stmik-amik-riau.ac.id, yoyonefendi@stmik-amik-riau.ac.id
}

\begin{abstract}
Increasing technological developments are marked by the many innovative new technological discoveries produced by big companies with increasingly keen competition in meeting their customers' needs. SMA Negeri 1 Sawahlunto is one of the favorite educational institutions in Sawahlunto. As we know that now every institution / educational institutions vying in the delivery of information and promotion in various ways, such as through electronic media, newspapers, and others. One form of electronic media promotion that utilizes the science of technology is by displaying information or promotion based on the website. Publication of information and promotion through an online site SMA Negeri 1 Sawahlunto, will provide effectiveness and efficiency for people who want to get school information without having to come directly to SMA Negeri 1 Sawahlunto. With the development of web-based information systems, is expected to produce a quality system in the delivery of information and promotion at SMA Negeri 1 sawahlunto.
\end{abstract}

Keywords: Information Systems, Promotion, Web

\section{PENDAHULUAN}

Tidak dapat dipungkiri bahwa sebuah informasi memiliki arti yang sangat penting bagi manusia saat ini. Disaat manusia memulai suatu kegiatan atau suatu pekerjaan akan diawali dengan mencari informasi terlebih dahulu. Ini dilakukan untuk mengurangi kesalahan saat memulai suatu pekerjaan yang tentunya informasi yang didapat haruslah benar-benar relevan, akurat dan up to date.

Berbagai cara dilakukan dalam menyampaikan informasi yang benarbenar berkualitas. Dan salah satunya dengan menampilkan atau mempublikasikan informasi di internet melalui sebuah situs atau yang lebih dikenal dengan Web. Cara penyajian data dan bentuk informasi yang disampaikan melalui Web memiliki kelebihan dimana informasi yang disajikan tersebut dapat diakses kapanpun, dimanapun dan oleh siapapun orang yang ingin mengaksesnya sesuai ketentuan yang berlaku. Sehingga dengan adanya web akan lebih memudahkan orang untuk mempublikasikan informasi yang berkaitan.

SMA Negeri 1 Sawahlunto yang merupakan salah satu sekolah menengah umum favorit di Kota Sawahlunto memiliki kompleksitas perputaran kegiatan untuk seluruh komponen yang ada didalamnya. Letaknya yang strategis di pintu masuk kota wisata ini menambah kenyamanan sekolah ini. Selain itu sekolah ini memiliki daya saing yang cukup tinggi dibidang akademik untuk wilayah Sumatera Barat bahkan tingkat Nasional.

Dengan mengamati potensi-potensi besar yang ada di sekolah ini dibutuhkanlah suatu cara penyampaian informasi yang dapat mempublikasikan promosi sekolah ini.

\section{METODE PENELITIAN}

Metodologi penelitian ini dilakukan secara sistematik agar mendapatkan alur kerja yang baik yang dapat digunakan sebagai pedoman untuk peneliti dalam melaksanakan penelitian. Mendefinisikan masalah atau memberikan penjelasan 
terhadap permasalahan yang akan diteliti secara terstruktur ataupun sistematis.

Langkah analisa masalah adalah langkah untuk dapat memahami masalah yang telah ditentukan ruang lingkup atau batasnya.Untuk mempermudah dalam melakukan analisis masalah maka perlu ditentukan analisa dari sistem yang sedang berjalan.Tahapan analisis harus dilakukan dengan teliti agar diketahui detail yang ada dalam sistem yang berjalan saat ini. Hal-hal yang akan dianalis is terdiri dari :

1. Analisis Masalah

2. Analisis Sistem yang sedang berjalan

3. Analisis Kebutuhan Non Fungsional

4.Analisis Spesifikasi Kebutuhan Perangkat Lunak

5.Analisis Spesifikasi Kebutuhan Perangkat Lunak

6. Analisis Aturan Bisnis Sistem Yang Akan Dibangun.

\section{HASIL DAN PEMBAHASAN}

\subsection{HASIL}

Aliran

sistem

informasi

menggambarkan perpindahan data dari satu entiti ke entiti lainnya yang nantinya akan menghasilkan suatu proses sistem informasi yang ada. Dalam aliran sistem informasi baru ini ada lima entiti yang terlibat langsung yaitu web admin, kepala sekolah, siswa, guru dan masyarakat

Setelah melakukan analisa dan mengetahui kebutuhan pada SMA Negeri 1 Sawahlunto dalam hal menyebarkan informasi seputar sekolah maka, penulis mencoba untuk melakukan perancangan sistem yang baru dengan menggunakan media yaitu komputer dan internet sehingga nantinya dapat membantu dan mempermudah SMA ini dalam melayani dan menyebarkan informasi seputar sekolah guna untuk meningkatkan kualitas sekolah.

Penerapan sistem informasi yang dimaksud disini yaitu merancang sebuah sistem informasi yang berbasiskan website dengan media internet dimana website akan berperan sebagai alat bantu dalam penyebaran informasi

Seperti yang diuraikan diatas tadi bahwa website SMA Negeri 1 Sawahlunto ini memiliki 5 sub bagian, yang akan menggunakan sistem berbasis web ini maka Untuk lebih jelasnya dapat dilihat pada keterangan berikut:

Web admin merupakan bagian yang mengatur penggunaan website pada website SMA Negeri 1 Sawahlunto. Bagian web admin akan menampilkan website SMA Negeri 1 Sawahlunto di internet, dengan berbagai informasi yang ingin dipublikasikan oleh sekolah atau seputar informasi tentang sekolah. Selanjutnya pihak sekolah mengajak para siswa untuk menggunakan teknologi internet. Sehingga siswa-siswa dapat aktif dalam mencari menuntut ilmu pengetahuan, website ini juga dapat berguna untuk siswa dalam menyampaikan seluruh kegiatan sekolah. Yang mana siswa dapat mengirim datanya di website hingga sampai pada web admin.Siswa Akan memberikan proposal kegiatan kesiswaan dan akan disetujui oleh Kepala sekolah dan guru-guru pembimbing. Seterusnya proposal kegiatan yang disetujui tersebut akan diberikan kepada web admin dan akan diupload bersama data-data siswa, guru dan kepala sekolah yang lain. Untuk lebih jelasnya aliran sistem informasi Website SMA Negeri 1 Sawahlunto yaitu sebagai berikut:

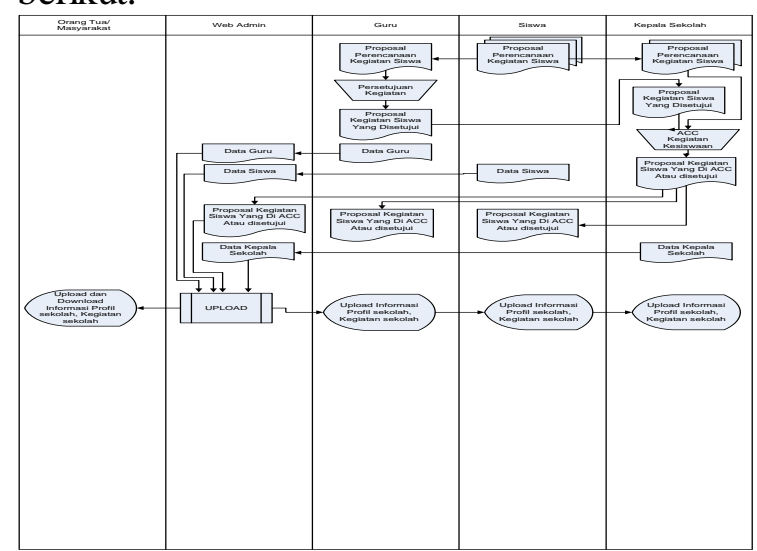

Gambar 3.1 Aliran Sistem Informasi Website SMA N 1 Sawahlunto 
Context diagram adalah gambaran sistem secara logical, gambaran ini tidak tergantung pada perangkat keras, perangkat lunak, atau organisasi file. Suatu contex diagram selalu mengandung satu proses saja (diberi nomor proses 0), proses ini mewakili proses dari keseluruhan sistem. Contex diagram menggambarkan hubungan input / output antara sistem dengan dunia luarnya. Dari contex diagram ini akan digambarkan dengan lebih rinci lagi yang disebut dengan overview atau level 0 .

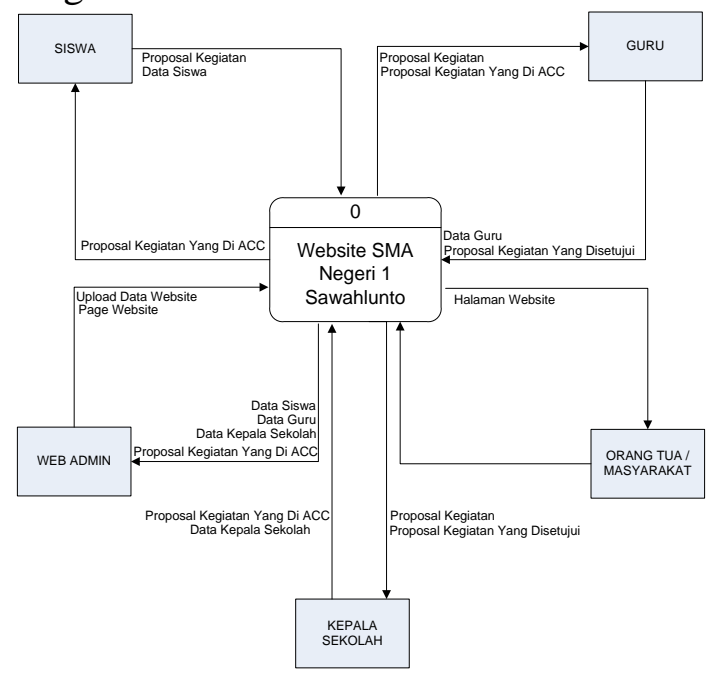

Gambar 3.2 Context Diagram

DFD level 0 merupakan penjabaran dari contex diagram seperti yang dapat pada gambar 3.3 berikut:

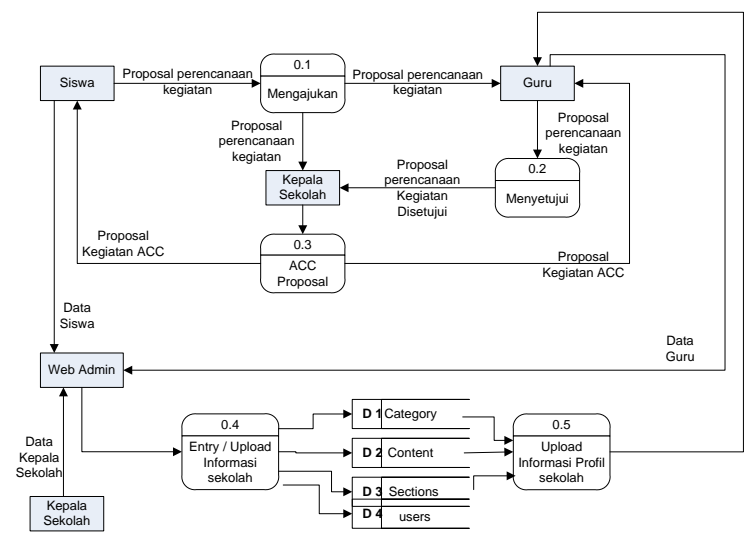

Gambar 3.3 Data Flow Diagram (DFD) Level 0

Entity Relatioship Diagram adalah suatu model jaringan kerja (Network) yang menguraikan susunan data yang distore dari sistem secara abstrak. Entity Relationship Diagram menunjukan hubungan antar entity didalam sistem, entity adalah suatu tempat, benda yang semuanya memiliki nama yang umum.Bentuk ERD yang dirancang terlihat dalam gambar 3.4 berikut :

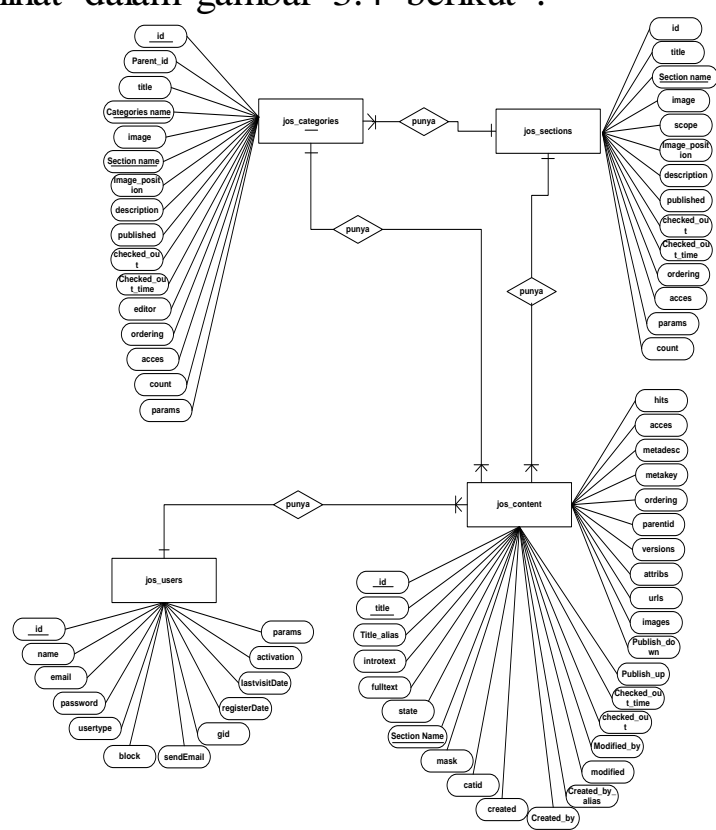

Gambar 3.4 Entity Relationship Diagram (ERD)

Stuktur program yang digunakan yaitu struktur program halaman utama dan halaman login.Halaman utama menampilkan informasi dari database.Informasi tersebut dikemas sedemikian rupa peletakan atau menumenunya. Masing-masing kategori diberikan halaman tersendiri dengan memanfaatkan teknik templating yang dimaksudkan untuk memisahkan content dengan layout. Sehingga memudahkan dalam pengelolaan content dan siap untuk menerima perubahan disain layout nantinya.

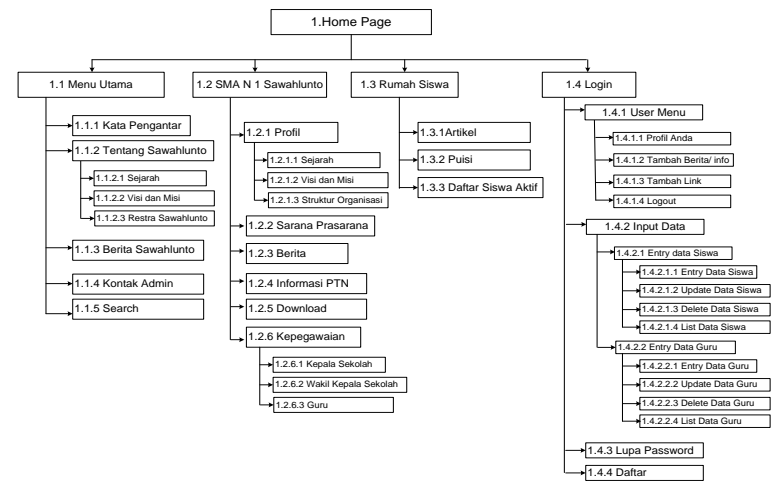

Gambar 4.5 Struktur Program Website SMA N 1 Sawahlunto 


\subsection{PEMBAHASAN}

Halaman utama untuk public ini, terdiri dari menu home, berita,kontak admin, profil, download, kepegawaian, daftar siswa aktif, login admin. Pengunjung hanya dapat melihat info mengenai home, profil, berita, dan melakukan pendaftaran login user untuk menjadi member.

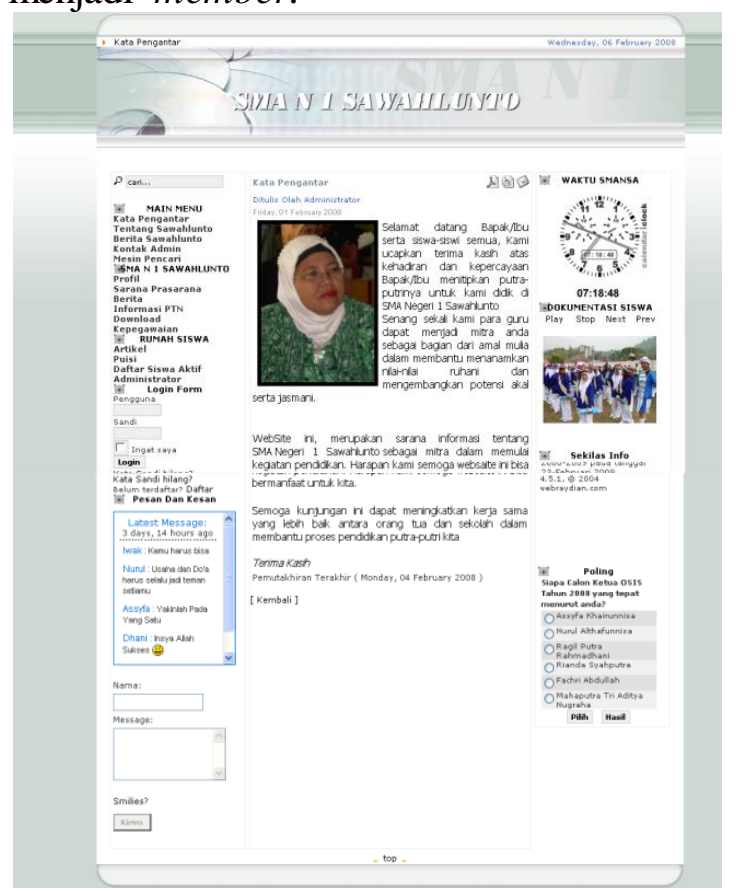

Gambar 4.6Tampilan Menu utama Website SMA N 1 Sawahlunto

\section{SIMPULAN}

Setelah melakukan penelitian pada SMA Negeri 1 Sawahlunto, maka dapat disimpulkan sebagai berikut:

1. Apabila orang tua atau masyarakat ingin mengetahui tentang informasi yang berkaitan dengan SMA Negeri 1 Sawahlunto maka mereka harus datang langsung ke SMA Negeri 1 Sawahlunto untuk menanyakannya langsung kepada pihak sekolah yang bersaangkutan. Itupun akan terpenuhi apabila pihak sekolah yang bersangkutan tersebut ada di tempat.

2. Akibat dari kesulitan mendapatkan informasi yang rumit seperti itu, maka terjadi ketidakefesienan dalam segi waktu dan biaya.
3. Terkadang ada kekecewaan diantara masyarakat ataupun orang tua yang datang untuk mencari informasi seperti mencari Kepala Sekolah sedangkan Kepala sekolah sendiri sedang tidak di tempat. .

4. Dengan adanya situs atau Sistem Informasi berbasis web pada SMA Negeri 1 Sawahlunto akan sangat membantu pihak sekolah dalam memberikan pelayanan yang baik kepada masyarakat, orangtua siswa, siswa itu sendiri ataupun user yang membutuhkan dalam mengetahui profil dan informasi-informasi mengenai SMA Negeri 1 Sawahlunto.

5. Dengan merancang sebuah antarmuka berbasiskan web diharapkan dapat menangani sistem secara online, dan untuk perkembangan lebih lanjut dapat di implementasikan pada jaringan internet sehingga semua orang dapat mengakses sendiri segala profil dan informasi publik tentang SMA Negeri 1 Sawahlunto.

6. Melalui dunia maya kita dapat melakukan aktifitas apa saja layaknya seperti dunia real yang dihadapi seharihari.

\section{UCAPAN TERIMAKASIH}

Ucapan terimakasih kepada STMIK Amik Riau, SMA Negeri 1 Sawahlunto dan semua pihak yang telah membantu atas bantuan melakukan penelitian ini.

\section{DAFTAR PUSTAKA}

Sidik, Betha, Ir. MySQL.Informatika. Bandung 2005.

I Made Gunadi, Lirva32. Joomla! Website Magic Dengan Joomla! Bikin Website semudah memasak mie Instan.Jasakom. Jakarta. 2007.

Firdaus. 7 Jam Belajar Interaktif PHP \& $M y S Q L$ dengan Dreamweaver.Maxikom. Palembang. 2007.

Purwanto, MT.Heru, S.Kom. Membangun Website Interaktif Sekolah. Andi Offset. Yogyakarta. 2007 
Hidayatullah, A Taufik. Belajar Adobe Photoshop 7.0. Surabaya:Indah Surabaya. 2003.

H.A Moduto, Rahmat Hidayat, Yuhefizar. 2006 .Cara Mudah Membangun Website Interaktif menggunakan Content management Sistem. Jakarta:Gramedia

Yani, Ahmad. Panduan Membangun Jaringan Komputer. PT.Kawan Pustaka. Jakarta. 2007 